University of Nebraska - Lincoln

DigitalCommons@University of Nebraska - Lincoln

2006

\title{
Phylogenetic Analysis of the cardini Group of Drosophila with Respect to Changes in Pigmentation
}

Jennifer A. Brisson

University of Nebraska-Lincoln, jennifer.brisson@rochester.edu

Jason Wilder

Williams College, jwilder@williams.edu

Hope Hollocher

University of Notre Dame, hope.hollocher.1@nd.edu

Follow this and additional works at: https://digitalcommons.unl.edu/bioscifacpub

Part of the Life Sciences Commons

Brisson, Jennifer A.; Wilder, Jason; and Hollocher, Hope, "Phylogenetic Analysis of the cardini Group of Drosophila with Respect to Changes in Pigmentation" (2006). Faculty Publications in the Biological Sciences. 43.

https://digitalcommons.unl.edu/bioscifacpub/43

This Article is brought to you for free and open access by the Papers in the Biological Sciences at DigitalCommons@University of Nebraska - Lincoln. It has been accepted for inclusion in Faculty Publications in the Biological Sciences by an authorized administrator of DigitalCommons@University of Nebraska - Lincoln. 


\title{
Phylogenetic Analysis of the cardini Group of Drosophila with Respect to Changes in Pigmentation
}

\author{
Jennifer A. Brisson ${ }^{1}$, Jason Wilder² and Hope Hollocher (hope.hollocher.1@nd.edu) ${ }^{3}$ \\ ${ }^{1}$ Formerly: Washington University, St. Louis, Missouri, USA; Currently: University of Nebraska-Lincoln, Lincoln, Nebraska, USA \\ ${ }^{2}$ Formerly: Princeton University, Princeton, New Jersey, USA; Currently: Williams College, Williamstown, Massachusetts, USA \\ ${ }^{3}$ University of Notre Dame, Notre Dame, Indiana, USA
}

\begin{abstract}
Phenotypic variability is the engine that drives future diversification with the expectation that polymorphic ancestors give rise to descendants harboring a subset of the ancestral variation. Here we examine evolutionary transitions from polymorphism to monomorphism in a visually striking New World radiation of fruit flies, the Drosophila cardini group. This group is distributed across the Americas and the Caribbean islands and exhibits a wide spectrum of abdominal pigmentation variation. Specifically, the $D$. dunni subgroup consists of Caribbean island endemics, each of which is monomorphic for its pigmentation pattern, with an interspecific cline of pigmentation across the islands. The D. cardini subgroup consists of American continental species with wide-ranging distributions and intraspecifically variable abdominal pigmentation. We determined the phylogeny of 18 species and subspecies using three nuclear and three mitochondrial regions analyzed with maximum parsimony, maximum likelihood, and Bayesian methods. The topology produced from a combined dataset exhibited high support values at all nodes, and differed from earlier phylogenetic hypotheses based on polytene chromosome inversion patterns and isozyme data. We find that the $D$. dunni subgroup species, with the exception of D. belladunni, are derived from a single source not of direct South American origin and their dispersal across the islands of the Caribbean does not follow a simple stepping-stone model. Morphological changes in pigmentation across the island species are incongruent with the colonization history of the group indicating that natural selection may have played a role in the determination of this character. Finally, we demonstrate that monomorphic species have arisen independently from polymorphic ancestors two to three times.
\end{abstract}

Key words: Abdominal pigmentation, Caribbean, Drosophila cardini group, interspecific cline, polymorphism.

Received September 30, 2005. Accepted April 7, 2006.

Selection on pigmentation is ubiquitous and impacts phenotypic diversity across a wide range of organisms. It has been studied extensively in invertebrates (e.g., Daphnia, Drosophila, ladybirds, butterflies, and moths) as well as several vertebrates (e.g., birds, fish, rodents and humans), and has been found to result from diverse evolutionary pressures, including varying physical environments (i.e., temperature, UV radiation, and relative humidity), predator evasion, and sexual selection (Mayr 1963; Majerus 1998; Ellers and Boggs 2003; True 2003). Changes in pigmentation are most commonly recognized as responses to environmental conditions that vary on microgeographic scales as seen in the rapid frequency shifts of melanic forms of Biston betularia moths in response to local pollution levels (Majerus 1998), adap tation of pocket mice to specific substrates (Nachman et al. 2003), and adaptation of melanic Daphnia to increased UV exposure in clear pools (Hebert and Emery 1990).

The Drosophila cardini group, first described by Sturtevant (1942), offers an unparalleled system in which to understand both the functional and evolutionary mechanisms underlying changes in Drosophila pigmentation. The group consists of a total of 16 described species (Table 1) inhabiting different areas of Neotropical America (Heed and Russell 1971) and is characterized by highly polymorphic pigmentation appearing not just as changes in the intensity of pigmentation, but also in the pattern of abdominal pigmentation among its members. The group has radiated equally on the Caribbean islands (the $D$. dunni subgroup) and the neighboring mainland (the D. cardini subgroup) (Heed 1962), providing a valuable dichotomy between island and continental patterns of pigmentation evolution in a single system. The $D$. dunni subgroup is remarkable in that each species is genetically fixed for its particular abdominal pigmentation pattern. These monomorphic species as a group exhibit an interspecific cline in pigmentation across the Caribbean islands, with lighter species in the north and darker species in the south (Heed and Krishnamurthy 1959; Hollocher 1996; Hollocher et al. 2000a). Such a cline in pigmentation is an indication that natural selection on this trait may have played an important role during speciation. Alternatively, this step cline may not be the result of selection, but rather represents the remnants of two separate colonization streams, one comprising light species and the other dark.

In contrast to the island species, similar ranges of pigmentation variation exist within species of the $D$. cardini subgroup on the mainland. These species are characterized by wideranging distributions and highly polymorphic intraspecific abdominal pigmentation patterns that vary from almost completely pigmented to nearly unpigmented (da Cunha 1949; Heed 1963; Martinez and Cordeiro 1970). Interestingly, the developmental control of abdominal pigmentation in the D. cardini subgroup is variable as well: some intraspecific polymorphisms have been categorized as environmentally influenced, and others genetically controlled (da Cunha 1949; Heed 1963; Martinez and Cordeiro 1970).

Several phylogenetic hypotheses for the $D$. cardini group have been proposed previously, based primarily on the analysis of chromosomal inversion patterns (Heed and Russell 
TABLE 1. Drosophila species distributions ${ }^{1}$.

\begin{tabular}{lll}
\hline \hline \multicolumn{1}{c}{ Species } & Subgroup & \\
\hline D. bedicheki & cardini & Trinidad \\
D. cardini & cardini & Florida to Brazil \\
D. cardinoides & cardini & Mexico to Brazil \\
D. parthenogenetica & cardini & Mexico to Brazil ${ }^{2}$ \\
D. neomorpha & cardini & Mexico to Brazil \\
D. polymorpha & cardini & South America \\
D. neocardini & cardini & South America \\
D. procardinoides & cardini & Andes of Bolivia and Peru \\
D. acutilabella & dunni & Florida, Cuba, Jamaica, Hispaniola \\
D. antillea & dunni & St. Lucia \\
D. arawakana & dunni & St. Kitts to Dominica (D. arawakana arawakana and D. arawakana kittensis) \\
D. belladunni & dunni & Jamaica \\
D. caribiana & dunni & Martinique \\
D. dunni & dunni & Puerto Rico and St. Thomas (D. dunni dunni and D. dunni thomasensis) \\
D. nigrodunni & dunni & Barbados \\
D. similis & St. Vincent and Grenada (D. similis similis and D. similis grenadensis) \\
\hline
\end{tabular}

${ }^{1}$ Distributions are those reported in Heed and Krishnamurthy (1959), Futch (1962), and Heed (1962), in addition to those otherwise noted.

2 Range extensions for these two species were recently reported in De Toni et al. (2005).

${ }^{3}$ Recent collections indicate that this species is the most widely distributed of the dunni subgroup, and is found on St. Kitts, Nevis, Montserrat, Guadeloupe and Dominica (Wilder and Hollocher 2003)

1971), but also on the morphology of male genitalia (Heed 1962), patterns of reproductive isolation (Heed and Krishnamurthy 1959), and, more recently, isozyme dissimilarity (Napp and Cordeiro 1981). This paper evaluates the evolutionary relationships of the $D$. cardini group species with DNA sequence data from six loci: the cytochrome oxidase II (COII), cytochrome B (cytB), and NADH dehydrogenase subunit I, and $16 S$ ribosomal RNA (16S) mitochondrial gene regions, as well as the phosphogluconate dehydrogenase ( $p g d)$, myosin light chain $(\mathrm{mlc})$, and the $\mathrm{Cu}, \mathrm{Zn}$ superoxidase dismutase (sod) nuclear genes. We use the resulting phylogeny to test competing hypotheses of island biogeography in the $D$. dunni subgroup, and to investigate patterns of monomorphism and polymorphism in the evolution of abdominal pigmentation in the group.

\section{Materials and Methods}

\section{Drosophila Strains}

The species designations used in this study are the same as those described by W. Heed and his colleagues (Heed and Krishnamurthy 1959; Futch 1962; Heed and Russell 1971). Flies were either collected from the field or obtained from the National Drosophila Species Resource Center (NDSRC) formerly in Bloomington, Indiana, and now housed in Tucson, Arizona. All species designations of lines sequenced (whether from the field or from NDSRC) were confirmed by matching individuals from the stock to the published descriptions of male genitalia and abdominal pigmentation, (Heed and Krishnamurthy 1959; Heed 1962; Vilela et al. 2002), in some cases with the help of $W$. Heed and his colleagues at the University of Arizona, Tucson.

The species obtained from NDSRC and the field for sequence analysis, their locale, and stock numbers are as in Table 2. Three additional Drosophila species obtained from the NDSRC were chosen to serve as outgroups based on the species group relationships described in Remsen and O'Grady (2002): D. unipunctata (from the tripunctata group), Caripe, Venezuela (15220-2411.1); D. ornatipennis (from the calloptera group), St. Vincente, Cuba (15160-2121.2); and D. guttifera (from the quinaria group), Fayetteville, Arkansas (15130.1971.2).

Drosophila neomorpha and D. bedicheki are not available from NDSRC. To remedy this, D. neomorpha collected by K. M. Rodriguez-Clark in January 1997 from Gamboa, Panama, and J. Brisson from La Selva, Costa Rica, were used for analysis. Drosophila bedicheki, only collected once in Trinidad in 1964 by S. Bedichek Pipkin (Heed and Russell 1971), is a relatively rare species and was not available for analysis. One stock obtained from the NDSRC, D. similis grenadensis, Grenada (15182-2321.0), is not a sample of the species intended, but rather is $D$. dunni, as indicated by its pigmentation pattern, male genitalia, and ability to hybridize with other species (Wilder and Hollocher 2003; H. Hollocher, unpubl. data). Sequence data were obtained from this NDSRC stock only to confirm our suspicion that this stock was contaminated; therefore, the stock was not used in any of the final analyses. New samples of $D$. similis similis and $D$. similis grenadensis collected by H. Hollocher in July 1996 from Vermont, St. Vincent, and Grand Etang, Grenada, respectively, were used in the final sequence analysis.

Classification of Species as Monomorphic or Polymorphic

A series of previous studies reported the monomorphic or polymorphic abdominal pigmentation state of each of the species investigated here based on field collections or laboratory studies (Streisinger 1946; da Cunha 1949, 1955; Stalker 1953; Heed and Krishnamurthy 1959; Heed 1962, 1963; Machado 2001; Brisson et al. 2005). More recent field collections have confirmed the observation of monomorphism of the island species, D. belladunni, D. dunni, D. arawakana, D. caribiana, D. antillea, D. similis, and D. nigrodunni $(\mathrm{H}$. Hollocher, unpubl. data) and the polymorphism of D. cardini, $D$. cardinoides, D. neomorpha, and D. neocardini (J. Brisson and D. De Toni, unpubl. data).

\section{Genetic Loci Sampled}

Genomic DNA was isolated from individual flies using the Dneasy Tissue Kit (Qiagen) or the protocol of Rand (1992). 
TABle 2. Strain of each Drosophila species used in this study. NDSRC, National Drosophila Species Resource Center; HH, Hope Hollocher; JAB, Jennifer A. Brisson; KMRC, Kathryn M. Rodríguez-Clark; JAW, Jason A. Wilder; EGD/EGS, Eric G. Dyreson and Erika G. Schielke.

\begin{tabular}{|c|c|c|c|c|c|}
\hline Species & Strain & $c y t B$ & $\mathrm{COII}$ and $16 \mathrm{~S}$ & $m l c$ and $p g d$ & sod \\
\hline \multirow[t]{2}{*}{ D. antillea } & NDSRC St. Lucia 15182-2251.0 & $\mathrm{X}$ & $\mathrm{X}$ & $\mathrm{X}$ & $\mathrm{X}$ \\
\hline & HH St. Lucia & $\mathrm{X}$ & & & \\
\hline \multirow[t]{5}{*}{ D. arawakana arawakana } & HH Mt. Joy, Dominica & $\mathrm{X}$ & $\mathrm{X}$ & $\mathrm{X}$ & \\
\hline & HH Syndicate, Dominica & $\mathrm{X}$ & & & \\
\hline & NDSRC Montserrat 15182-2261.2 & $\mathrm{X}$ & $\mathrm{X}$ & & \\
\hline & JAW Guadeloupe & & & & $\mathrm{X}$ \\
\hline & NDSRC Guadeloupe 15182-2261.0 & & $\mathrm{X}$ & $\mathrm{X}$ & \\
\hline \multirow[t]{2}{*}{ D. arawakana kittensis } & EGD/EGS Nevis & $\mathrm{X}$ & $\mathrm{X}$ & $\mathrm{X}$ & \\
\hline & EGD/EGS St. Kitts & & & & $\mathrm{X}$ \\
\hline \multirow[t]{2}{*}{ D. acutilabella } & NDSRC Florida 15181-2171.9 & $\mathrm{X}$ & $\mathrm{X}$ & $\mathrm{X}$ & $\mathrm{X}$ \\
\hline & NDSRC Cuba 15181-2171.2 & & $\mathrm{X}$ & & \\
\hline D. belladunni & NDSRC Jamaica 15182-2271.1 & $\mathrm{X}$ & $\mathrm{X}$ & $\mathrm{X}$ & $\mathrm{X}$ \\
\hline \multirow[t]{5}{*}{ D. cardini } & NDSRC Brazil 15181-2181.3 & $\mathrm{X}$ & & $\mathrm{X}$ & \\
\hline & NDSRC Cuba 15181-2181.9 & & $\mathrm{X}$ & & \\
\hline & HH Constanza, Dominican Republic & & $\mathrm{X}$ & & \\
\hline & HH Cuba & & & & $\mathrm{X}$ \\
\hline & HH Finquita Gloria 3F, Dominican Republic & & & & $\mathrm{X}$ \\
\hline \multirow{2}{*}{ D. cardinoides } & NDSRC Columbia 15181-2191.0 & $\mathrm{X}$ & & $\mathrm{X}$ & \\
\hline & NDSRC Mexico 15181-2191.8 & & $\mathrm{X}$ & & $\mathrm{X}$ \\
\hline \multirow[t]{2}{*}{ D. caribiana } & HH Martinique & $\mathrm{X}$ & & $\mathrm{X}$ & \\
\hline & NDSRC Martinique 15182-2281.0 & $\mathrm{X}$ & $\mathrm{X}$ & & $\mathrm{X}$ \\
\hline \multirow[t]{2}{*}{ D. dunni dunni } & HH Puerto Rico & $\mathrm{X}$ & $\mathrm{X}$ & $\mathrm{X}$ & \\
\hline & NDSRC Puerto Rico 15182-2291.0 & & $\mathrm{X}$ & & $\mathrm{X}$ \\
\hline D. dunni thomasensis & NDSRC St. Thomas 15182-2301.0 & $\mathrm{X}$ & $\mathrm{X}$ & $\mathrm{X}$ & $\mathrm{X}$ \\
\hline D. neocardini & NDSRC Brazil 15181-2201.0 & $\mathrm{X}$ & $\mathrm{X}$ & $\mathrm{X}$ & $\mathrm{X}$ \\
\hline \multirow[t]{2}{*}{ D. neomorpha } & JAB Costa Rica & $\mathrm{X}$ & & $\mathrm{X}$ & \\
\hline & KMRC Panama & & $\mathrm{X}$ & & $\mathrm{X}$ \\
\hline \multirow[t]{3}{*}{ D. nigrodunni } & NDSRC Barbados 15182-2311.1 & $\mathrm{X}$ & $\mathrm{X}$ & $\mathrm{X}$ & $\mathrm{X}$ \\
\hline & HH Turner's Hall Woods, Barbados & $\mathrm{X}$ & & & \\
\hline & HH St. Nicholas Abbey, Barbados & $\mathrm{X}$ & & & \\
\hline \multirow[t]{2}{*}{ D. parthenogenetica } & NDSRC Sinaloa, Mexico 15181-2221.0 & $\mathrm{X}$ & $\mathrm{X}$ & $\mathrm{X}$ & \\
\hline & NDSRC Puebla, Mexico 15181-2221.1 & & $\mathrm{X}$ & & $\mathrm{X}$ \\
\hline \multirow{4}{*}{ D. polymorpha } & NDSRC Brazil 15181-2231.1 & $\mathrm{X}$ & $\mathrm{X}$ & $\mathrm{X}$ & \\
\hline & NDSRC Trinidad 15181-2231.2 & & $\mathrm{X}$ & & $\mathrm{X}$ \\
\hline & JAB São Paulo, Brazil & $\mathrm{X}$ & & $\mathrm{X}$ & \\
\hline & JAB Florianópolis, Brazil & $\mathrm{X}$ & & $\mathrm{X}$ & \\
\hline D. procardinoides & NDSRC Bolivia 15181-2241.0 & $\mathrm{X}$ & $\mathrm{X}$ & $\mathrm{X}$ & $\mathrm{X}$ \\
\hline D. similis grenadensis & HH Grenada & $\mathrm{X}$ & $\mathrm{X}$ & $\mathrm{X}$ & $\mathrm{X}$ \\
\hline D. similis similis & HH St. Vincent & $\mathrm{X}$ & $\mathrm{X}$ & $\mathrm{X}$ & $\mathrm{X}$ \\
\hline
\end{tabular}

Three mitochondrial regions and three nuclear loci were amplified from each species. The primers used for these loci are listed in Table 3. The three nuclear loci were portions of the X-linked pgd locus (Christensen and Lucchesi 1984), the autosomal $m l c$, and the autosomal $\mathrm{Cu}, \mathrm{Zn}$ sod gene. The mtDNA gene regions used were cytB and flanking regions, COII, and parts of NADH dehydrogenase subunit I and the $16 \mathrm{~S}$ gene regions. The mtDNA loci were sequenced directly, as was the $p g d$ locus, since only males were used. Amplification and sequencing of the sod locus is described in Wilder and Hollocher (2003). Amplicons from the mlc locus were cloned into the pSTBlue-1 vector using the Acceptor Vector cloning kit (Novagen, EMD Biosciences, Darmstadt, Germany). Cloned DNA was sequenced using the vector-specific primers T7 and U19 (Novagen) and at least two clones were sequenced for each species. Products of the sequencing reactions for $c y t B, m l c$, and $p g d$ were purified using CentriSep spin columns (Princeton Separations, Adelphia, NJ) and electrophoresed on a Basestation automated sequencer (MJ Research, BioRad Laboratories, Hercules CA). For the $16 \mathrm{~S}$ and COII datasets, direct double-stranded cycle sequencing was performed using the fmol (Promega, Madison, WI) sequencing system and run on $6 \%$ sequencing gels. Every locus was sequenced for some strain of each ingroup species. However, not every locus amplified for the outgroup species.

The regions of COII used in this study were originally described in Wilder and Hollocher (2003). The sod region included part of the first two exons and the intervening intron. The mlc region included the last three exons and intervening introns of the gene. The $p g d$ region sequenced included the second exon and surrounding noncoding regions. The $c y t B$ region sequenced includes a portion of the cytochrome $b$ gene, the complete serine tRNA, and part of NADH dehydrogenase subunit one.

\section{Sequence Alignment}

DNA sequences were aligned by hand in PAUP*4.0b8 (Swofford 2000) or by using the program ClustalW (Thompson et al. 1994). All three nuclear datasets contained a number of microsatellite and highly divergent regions; these were eliminated prior to analyses due to the ambiguity of 
TABle 3. Primers used for each locus

\begin{tabular}{|c|c|c|}
\hline Locus & Primers & Reference \\
\hline \multirow[t]{2}{*}{ pgd } & pgdfor: GGAGCCGACTCGCTNGARGAYATG & Brisson et al. 2004 \\
\hline & pgdrev: CGCGGCCTCGTGNCCNCCNGGCAT & Brisson et al. 2004 \\
\hline \multirow[t]{4}{*}{$m l c$} & mlcf: ATTTTGCAGTTGTAGTAGCAGA & this study \\
\hline & mlcr: AACGAGAAGAAGATCAAGCTGG & this study \\
\hline & mlcmid1: TGCACCATCGTTTGATTTGT & this study \\
\hline & mlcmid2: TAGCGCATCTGGTCTGTCAC & this study \\
\hline \multirow{2}{*}{ sod } & $\mathrm{N}:$ CCTCTAGAAATGGTGGTTAAAGCTGT (AGCT) TGCGT & Wilder and Hollocher 2003 \\
\hline & C: CTTGCTGAGCTCGTGTCCACCCTTGCCCAGATCATC & Wilder and Hollocher 2003 \\
\hline \multirow[t]{4}{*}{$c y t B$} & 10941: TTGAGGAGCTACTGTTATTAC & Brisson et al. 2005 \\
\hline & 12580: TTGTTTAATAGGAATTCCTCAACC & Brisson et al. 2005 \\
\hline & 11841: GGTACATTACCTCGGTTTCGTTATGAT & Brisson et al. 2005 \\
\hline & 11670: ATGAGCTTGAACAAGCATATGTT & Brisson et al. 2005 \\
\hline \multirow[t]{4}{*}{ COII } & TL-2-J-3037(LeuA): ATGGCAGATTAGTGCAATGG & Spicer 1995 \\
\hline & TK-N-3785(LysB): GTTTAAGAGACCAGTACTTG & Spicer 1995 \\
\hline & A3772 (Eva): GAGACCATTACTTGCTTTCAGTCATCT & Brower and DeSalle 1994 \\
\hline & S3291 (Strom): TAATTTGAACTAT (C/T) TTACCIGC & Brower and DeSalle 1994 \\
\hline \multirow[t]{5}{*}{$16 S$} & ALF-1: GCATCACAAAAAGGTTGAGG & DeSalle 1995 \\
\hline & 16S-1 (KB1): GCTGGAATGAATGGTTGGACG & DeSalle 1995 \\
\hline & $16 S-2$ (KB2): TAATCCAACATCGAGGTCGC & DeSalle 1995 \\
\hline & 16S-3 (KB3): TATAATTTTGGGTGTAGCCG & DeSalle 1995 \\
\hline & 16S-4 (KB4): AATTTATTGCACTAATCTGCC & DeSalle 1995 \\
\hline
\end{tabular}

alignment. Protein-coding regions of the mtDNA dataset were translated into amino acids using MacClade (Maddison and Maddison 2000) for confirmation of alignment and to check for the integrity of the data. The separate sequences were concatenated into a single partitioned dataset in PAUP* for combined analyses. Heterogeneity among sites was determined with PAUP* for all taxa.

\section{Phylogenetic Analyses}

Maximum parsimony (MP) analyses. A heuristic search using 1000 replicates and tree bisection-reconnection (TBR) branch swapping was implemented in PAUP* (Swofford 2000). The resulting strict consensus trees are shown for each dataset. We used nonparametric bootstrapping (Felsenstein 1985) to assess node stability, with 1000 replicates of 10 random additions of taxa per replicate. Bremer support values (number of additional steps needed to accommodate alternative phylogenetic hypotheses; Bremer 1994) were determined using TreeRot (Sorenson 1999).

Maximum likelihood (ML) analyses. We first selected the best of 56 models for the dataset using ModelTest 3.04 (Posada and Crandall 1998). The chosen model was then used in a heuristic search for the maximum likelihood tree topology in PAUP* $^{*}$ using 500 replicates and tree bisection-reconnection (TBR) branch swapping. To obtain a measure of support for the ML trees, we used 500 bootstrap replicates with 10 random additions of taxa per replicate.

Bayesian analyses. The parameters determined in the ML analyses were input into MrBayes 3.0 (Huelsenbeck and Ronquist 2001). In the combined dataset, datasets were partitioned to use their corresponding model as determined by ModelTest. Four chains were run. For each dataset, 10 million generations were run with trees sampled every 1000 steps for a total sampling of 10,000 trees per run. The program Tracer (Rambaut and Drummond 2004) was used to visualize the resulting trees to determine the burn-in (i.e., when stability is reached when ln-likelihood scores of the sampled trees are plotted against generation time) and to check for a sin- gle peak in a histogram of tree maximum likelihood values, suggesting convergence. Analyses were run independently three times to compare for convergence as determined by similar ln-likelihood values and tree topologies at each run. In each case, the Bayesian analyses converged on similar lnlikelihood scores and topologies.

\section{Congruence Determination}

Congruence among datasets was assessed using incongruence length difference (ILD) tests (Farris et al. 1994, 1995) implemented in PAUP*. We performed the ILD test for each pairwise combination of genes under parsimony with 100 random addition sequences of taxa and 100 replicates to generate the null distribution. Significance was determined using Bonferroni-corrected $P$ values.

\section{Hypothesis Testing}

We tested a number of phylogenetic hypotheses regarding the $D$. cardini group. For each hypothesis tested, we created a new tree topology that represented that hypothesis. We then used that topology to constrain a heuristic search with 1000 replicates and random addition of taxa. The resulting strict consensus tree was then compared to the strict consensus tree produced by the total dataset without constraint using the Wilcoxon signed ranks test (Templeton 1983) as implemented in PAUP*. First, is the D. cardini subgroup monophyletic? To test this, we constrained the total data tree to make the $D$. cardini subgroup an independent radiation from the $D$. dunni subgroup (with $D$. acutilabella the sister taxon to the clade containing $D$. neocardini, $D$. parthenogenetica, $D$. cardinoides, and $D$. procardinoides). Second, can we resolve the conflict in the placement of $D$. neocardini as originally determined by the inversion and male genitalia data? To test this, we constrained the combined data tree to make D. neocardini the basal member of the clade containing $D$. acutilabella and the D. dunni subgroup species or to be a member of the D. neomorpha/D. polymorpha clade as suggested by the inver- 
TABLE 4. Data characteristics of each data partition for maximum parsimony analyses. CI, consistency index; RI, retention index.

\begin{tabular}{|c|c|c|c|c|c|c|c|c|c|c|}
\hline \multirow[b]{2}{*}{ Locus } & \multirow[b]{2}{*}{$\begin{array}{c}\text { Number } \\
\text { of taxa }\end{array}$} & \multirow{2}{*}{$\begin{array}{l}\text { Genetic } \\
\text { distances of } \\
\text { ingroups }\end{array}$} & \multirow[b]{2}{*}{$\begin{array}{l}\text { Genetic distances } \\
\text { including outgroups }\end{array}$} & \multicolumn{3}{|c|}{ Characters } & \multicolumn{4}{|c|}{ Trees } \\
\hline & & & & Total & Constant & $\begin{array}{l}\text { Parsimony- } \\
\text { informative }\end{array}$ & $\begin{array}{l}\text { Number } \\
\text { (islands) }\end{array}$ & Length & $\mathrm{CI}$ & RI \\
\hline pgd & 20 & $0.004-0.104$ & $0.004-0.165$ & 463 & 344 & 39 & $10(4)$ & 159 & 0.899 & 0.810 \\
\hline mlc & 20 & $0.005-0.060$ & $0.005-0.210$ & 815 & 592 & 85 & $2(6)$ & 332 & 0.837 & 0.708 \\
\hline sod & 21 & $0.011-0.172$ & $0.011-0.327$ & 768 & 325 & 238 & $4(3)$ & 903 & 0.743 & 0.641 \\
\hline$c y t B$ & 21 & $0.001-0.080$ & $0.001-0.121$ & 1466 & 1106 & 253 & $1(1)$ & 757 & 0.576 & 0.615 \\
\hline COII & 20 & $0.000-0.087$ & $0.000-0.123$ & 324 & 245 & 52 & $10(4)$ & 145 & 0.628 & 0.682 \\
\hline $16 S$ & 20 & $0.000-0.030$ & $0.000-0.073$ & 691 & 601 & 36 & $12(1)$ & 124 & 0.798 & 0.747 \\
\hline Combined mtDNA & 21 & $0.002-0.066$ & $0.002-0.110$ & 2484 & 1959 & 314 & $1(6)$ & 1037 & 0.604 & 0.627 \\
\hline Combined nuclear DNA & 21 & $0.008-0.096$ & $0.008-0.248$ & 2047 & 1308 & 332 & $12(1)$ & 1269 & 0.784 & 0.663 \\
\hline Combined data & 21 & $0.005-0.079$ & $0.005-0.161$ & 4528 & 3264 & 646 & $2(1)$ & 2315 & 0.700 & 0.637 \\
\hline
\end{tabular}

sion and male genitalia data, respectively. Third, what is the likely source of colonists for the $D$. dunni subgroup radiation? To investigate this we tested whether the D. neocardini, $D$. parthenogenetica, D. cardinoides, and D. procardinoides clade could substitute for the D. acutilabella and D. belladunni clade as the sister group to the remaining island species of the D. dunni subgroup. Fourth, what is the colonization history of the Caribbean species? We tested for either a north to south or south to north stepping-stone colonization history of the islands. Additionally, we constrained the combined data tree to contain a clade of the light species, D. arawakana and D. dunni, which was reciprocally monophyletic to a clade of the dark island species, D. caribiana, D. antillea, $D$. similis, and D. nigrodunni. This constrained tree was used to test the hypothesis there was one invasion of the islands by a light species from the north, and another invasion by a dark species from the south. Finally, is our overall molecular phylogeny concordant with previously generated inversion chromosome and isozyme phylogenies? To test this, we used the phylogeny of the entire $D$. cardini group based on inversion chromosomes (Heed and Russell 1971, W. B. Heed, pers. comm.) or isozyme data (Napp and Cordeiro 1981) to constrain our molecular topology.

Results

\section{Data Partitions and Base Composition}

For the six different datasets discussed here, total numbers of taxa and characters of each are listed in Table 4 . The number of taxa differed because some of the datasets had three

TABLE 5. Nucleotide composition of each locus separately as well as combined. The reported $P$-value is that of a chi-squared test of homogeneity of base frequencies across taxa.

\begin{tabular}{lccrcc}
\hline \hline \multirow{2}{*}{$\begin{array}{c}\text { Character } \\
\text { partition }\end{array}$} & \multicolumn{5}{c}{ Base frequency (\%) } \\
\cline { 2 - 5 } pgd & A & C & \multicolumn{1}{c}{ G } & T & $P$-value \\
\hline mlc & 26.2 & 25.1 & 19.2 & 29.5 & 1 \\
sod & 30.2 & 16.8 & 24.5 & 28.5 & 1 \\
cytB & 27.2 & 21.5 & 22.4 & 29.0 & 1 \\
COII & 41.9 & 14.1 & 9.1 & 34.8 & 1 \\
16S & 33.4 & 14.7 & 15.8 & 36.1 & 1 \\
Combined data & 41.2 & 14.2 & 7.9 & 36.7 & 1 \\
\hline
\end{tabular}

outgroups, and others had two. All three mtDNA datasets $(16 S, C O I I, c y t B)$ were aligned by hand, and no indels were observed. In contrast, all three of the nuclear datasets $(\mathrm{mlc}$, $p g d$, sod) had portions that were eliminated prior to analyses due to either the presence of microsatellites or ambiguous alignments. The minimum and maximum pairwise genetic distances with and without outgroup taxa for each locus are reported in Table 4. Chi-squared tests of base frequency homogeneity showed no across-taxa variation in composition for any of the data partitions ( $P=1$ for all; Table 5).

We created a total dataset consisting of a concatenation of the individual datasets. Because not all outgroups were available for each set, they were coded as unknown data for their respective missing partitions. Also, for each taxon, the exact same strain was not necessarily used (Table 2). We initially explored the amount of variation within versus between species using multiple individuals of many species and found that most of the species were well differentiated. Therefore, it should not matter which individual or strain was used in the combined analysis. However, some species did not always form monophyletic groups: those in the lineage containing $D$. cardinoides, $D$. procardinoides, and D. parthenogenet$i c a$, and those in the lineage of D. antillea, D. nigrodunni, and D. arawakana. We consider the implications of this result in the discussion.

Phylogeny Inference of Individual and Combined Datasets

We performed separate phylogenetic analyses for each of the three mtDNA datasets using MP, ML and Bayesian approaches. The resulting strict MP consensus trees, along with $\mathrm{MP}$ and ML nonparametric bootstrap values, Bremer support indices, and Bayesian posterior probabilities are shown in Figure 1A-C. No node with bootstrap support greater than 70 in the ML topology or a posterior probability of greater than 90 conflicted with the strict MP consensus tree. The individual character partitions resulted in a range of mostly compatible tree topologies with varying support values, with the $c y t B$ dataset exhibiting nodes with the strongest support. Although we used three distinct regions of mtDNA, the mtDNA genome is a single inherited unit, with no recombination. We therefore combined the three datasets to find the topology resulting from all of the mtDNA together (Figure 1D). For this combined analysis (and future combined analy- 
A

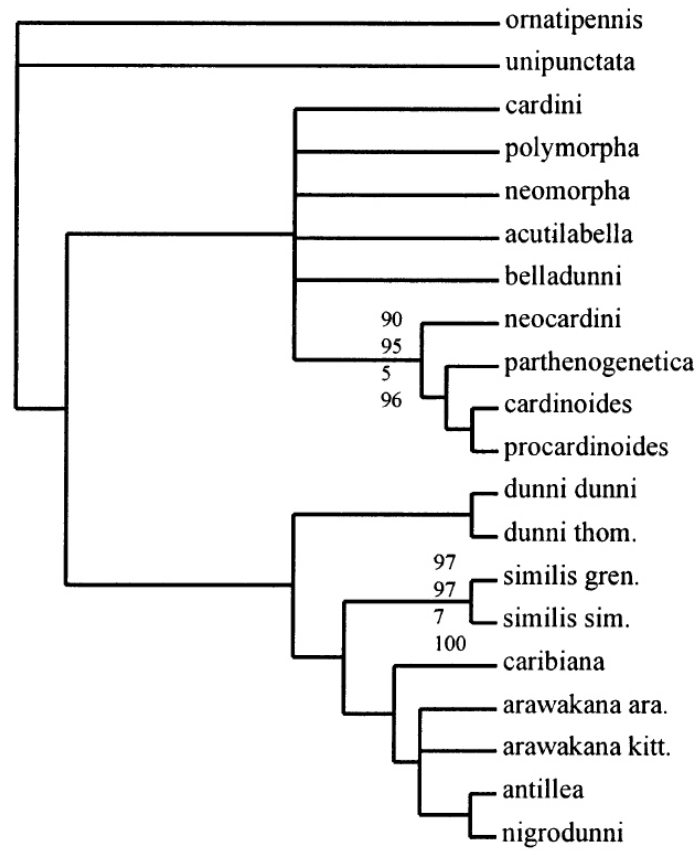

$\mathrm{C}$

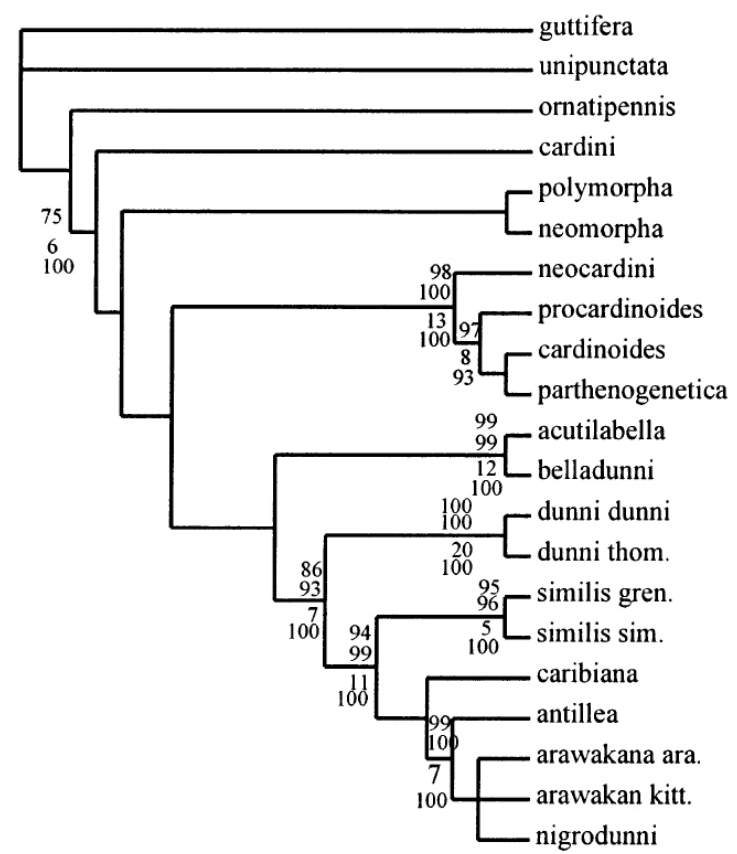

B

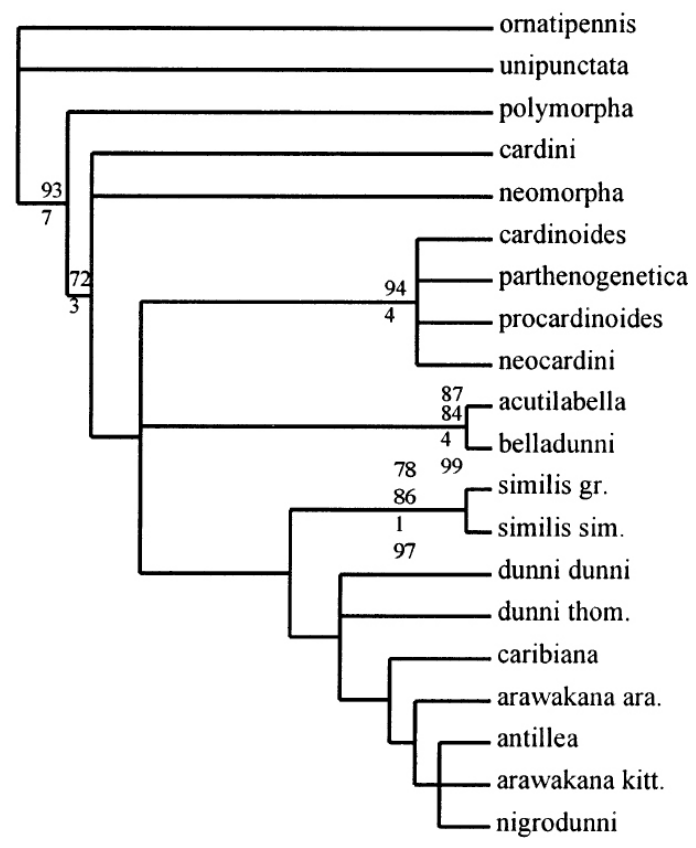

$\mathrm{D}$

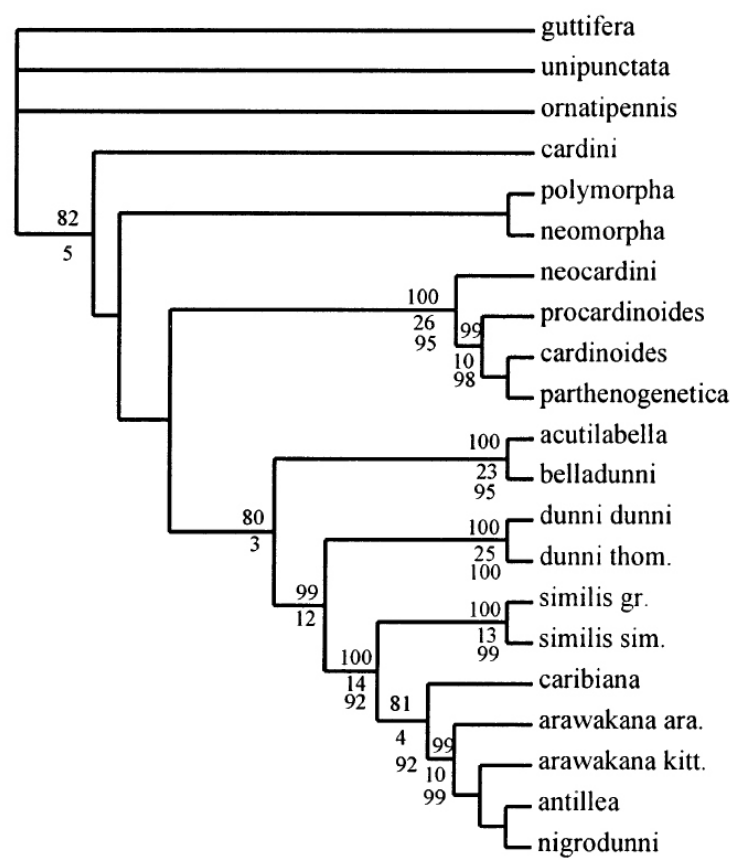

FIG. 1. Strict parsimony consensus trees of mtDNA datasets. The numbers associated with each node are the maximum likelihood (ML) bootstrap, the maximum parsimony bootstrap, the decay index, and the Bayesian posterior probability (top to bottom). Only bootstrap values greater than 70 and posterior probabilities greater than 90 are noted. (A) COII, (B) 16S, (C) cytB, (D) all mtDNA combined (note that there are no ML bootstrap values on this tree).

ses), we only present MP and Bayesian analyses. Maximum likelihood analysis was not used because the different data partitions had different likelihood models associated with them (Table 6) and thus using a single model of evolution for the combined data could potentially produce spurious re- sults, whereas the Bayesian analysis for multiple loci allows for the partitioning of each locus using a different likelihood model. As expected, the combined tree showed greatly improved branch support. Given the fact that mitochondrial sequences are not independent genealogical realizations, this 
TABLE 6. Maximum likelihood (ML) models determined by ModelTest for each locus. I, proportion of invariable sites.

\begin{tabular}{llcllc}
\hline \hline Locus & \multicolumn{1}{c}{ ML model } & $\begin{array}{c}\text { Gamma } \\
\text { shape }\end{array}$ & \multicolumn{1}{c}{ I } & $T$-ratio \\
\hline$p g d$ & JC + G & 0.3024 & 0 & - \\
mlc & HKY + I + G & 0.2633 & 0 & 0.8399 \\
sod & GTR + G & 0.8269 & 0 & - \\
cytB & GTR + I + G & 1.1405 & 0.6224 & - \\
COII & GTR + I + G & 1.5845 & 0.6671 & - \\
$16 S$ & GTR + G & 0.9413 & 0.7060 & - \\
\hline
\end{tabular}

improvement of branch support with the concatenated mtDNA data likely reflects increased power associated with additional informative sites.

Despite the modestly different tree topologies for the individual datasets, a number of relationships appeared consistently throughout each tree. A clade of $D$. parthenogenetica, $D$. procardinoides, and $D$. cardinoides was often recovered, with $D$. neocardini emerging as the sister taxon to this clade. All but one species of the D. dunni subgroup appeared as a single clade and displayed number of consistent relationships. First, what has been called the nigrodunni complex - D. nigrodunni, D. arawakana, and D. antillea - was often resolved as a single well-supported clade that also included D. caribiana. In three of the four topologies, $D$. similis was the sister taxon to the clade containing the nigrodunni complex, and D. dunni was sister taxon to that resulting clade. Drosophila acutilabella and D. belladunni were also well supported as sister taxa, but their relationship to the rest of the $D$. dunni subgroup was more ambiguous. Sometimes the D. belladunni/D. acutilabella clade appeared as sister taxon to the remaining members of the $D$. dunni subgroup (cytB and combined data), and other times its position was unresolved (COII and 16S). Generally, the more recent relationships were well resolved, especially in the combined mtDNA data tree. However, the deeper relationships, such as those among D. cardini, D. polymorpha, and $D$. neomorpha, remained unresolved by the mtDNA.

We performed similar analyses for the nuclear DNA datasets (Figure 2). Again, the separate (Figure 2A-C) and combined (Figure 2D) analyses identified a number of consistent relationships. First, in two of the three individual dataset topologies we observed a clade containing $D$. cardinoides, $D$. parthenogenetica, and D. procardinoides, although in all cases $D$. neocardini was not grouped with this clade as it had been with the mtDNA datasets. Instead, $D$. neocardini's placement was either unresolved or with the $D$. dunni subgroup with low support. The nuclear DNA topologies also supported the monophyly of the $D$. dunni subgroup and the placement of the sister taxa D. belladunni and D. acutilabella with it (although with shifting relationships). Overall, the nuclear DNA agreed with the mtDNA with regard to most recent relationships, and the combined nuclear DNA tree agreed with the relationships within the D. dunni subgroup species. Additionally, the nuclear DNA resolved a couple of deeper relationships. First, it strongly supported the monophyly of the $D$. cardini group as a whole, and second, it identified D. cardini as the species emerging from the most basal split within the group.

In the nuclear dataset results, there were differences among the tree-building methods. First, although the MP and ML mlc trees did not differ at any nodes with strong support, the MP and Bayesian trees did. The Bayesian analysis placed the two $D$. similis subspecies in a clade with the two D. dunni subspecies and D. arawakana kittensis, and D. caribiana was resolved as outgroup to that clade. Further, that entire clade was equally distant to $D$. nigrodunni and $D$. arawakana arawakana. Second, the tree resulting from the Bayesian analysis of the combined nuclear dataset was slightly more resolved than that of the ML or MP trees. The Bayesian tree placed $D$. neocardini as the outgroup species to the clade of D. acutilabella/D. belladunni plus the members of the D. dunni subgroup, with a posterior probability of 95 . Six of the 12 most parsimonious trees for this dataset also exhibited this relationship, although with an overall bootstrap support of 62.

\section{Combined Analysis}

We used ILD tests (Farris et al. 1994, 1995) to determine partitions of data that were incongruent with one another. With a Bonferroni correction, we did not reject homogeneity for any of the pairwise comparisons (Table 7). We therefore explored the results of phylogenetic analyses employing combined data from all loci.

When all the data are combined into one analysis, there are 677 parsimony-informative characters (472 with the outgroups removed) and two most parsimonious trees are recovered. These two trees differ in the placement of taxa within the D. nigrodunni complex. The nodes exhibited dramatically improved resolution (Figure 3). In this combined analysis, D. cardini emerged from the most basal node within the D. cardini group. Drosophila polymorpha and D. neomorpha formed a less-well-supported clade, which splits off from the rest of the tree after D. cardini. Extremely well supported was $D$. neocardini's placement as the outgroup species to the clade containing the remaining members of the $D$. cardini subgroup, D. procardinoides, D. cardinoides, and D. parthenogenetica. Also strongly supported was a monophyletic clade containing the majority of the island $D$. dunni subgroup species, which was nested within the $D$. cardini subgroup. The only D. dunni subgroup species not included in this monophyletic clade was $D$. belladunni. Instead of grouping with the other $D$. dunni subgroup species, D. belladunni paired with D. acutilabella of the $D$. cardini subgroup to form a sister clade to the remaining members of the $D$. dunni subgroup.

The Bayesian analysis produced a tree with an identical topology, with all nodes but one (the clade of D. polymorpha and D. neomorpha) having $95 \%$ or higher posterior probabilities (Figure 3).

\section{Hypothesis Testing}

Is the D. cardini subgroup monophyletic? - We investigated whether the primarily mainland D. cardini subgroup, as originally defined by Heed (1962) and illustrated in Figure 3 , is monophyletic. The Templeton test strongly rejected the monophyly of this subgroup (103 additional steps; $P<$ 0.0001).

Can we resolve the conflict in the placement of $\mathrm{D}$. neocardini as originally determined by the inversion and male genitalia data? - The Templeton test showed that neither placement was 
A

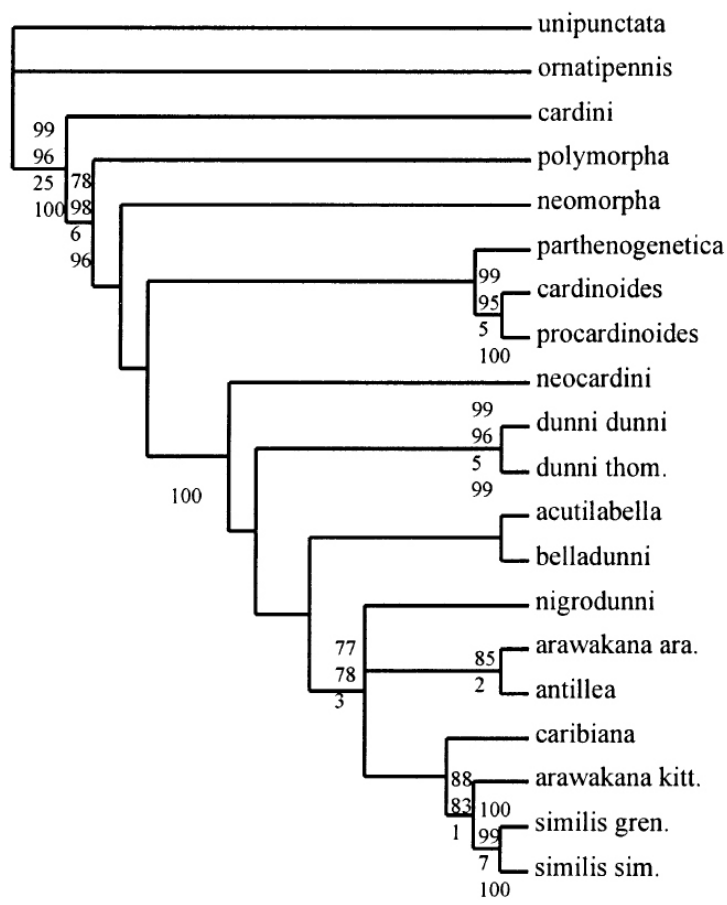

$\mathrm{C}$

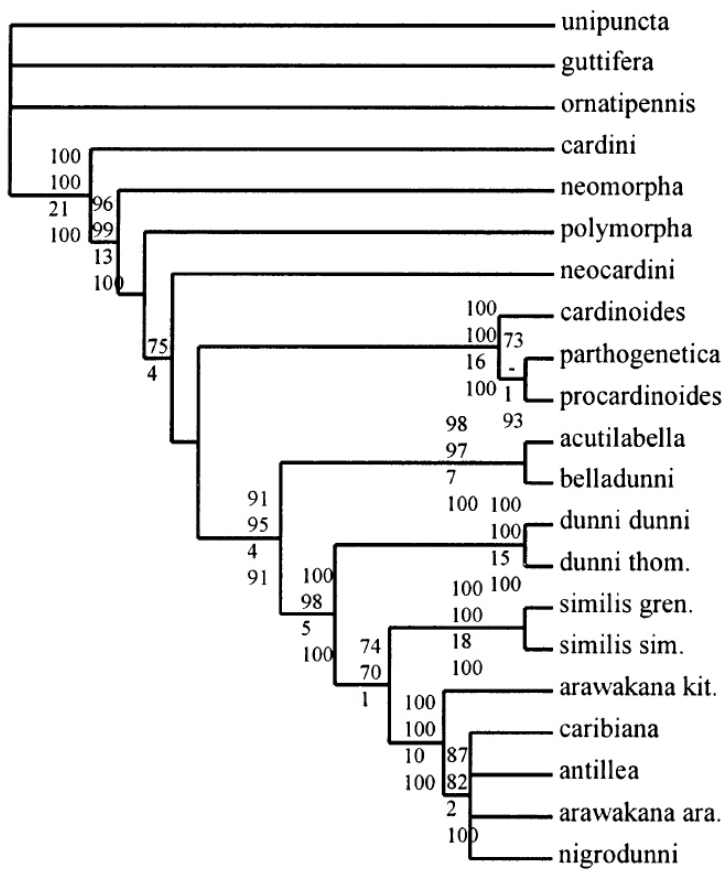

$\mathrm{B}$

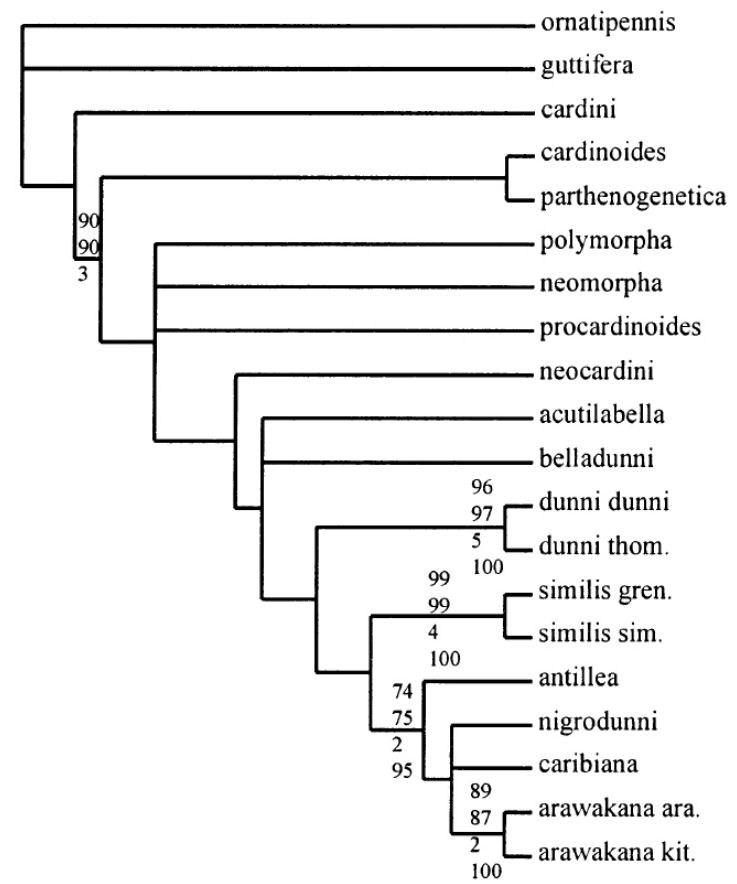

$\mathrm{D}$

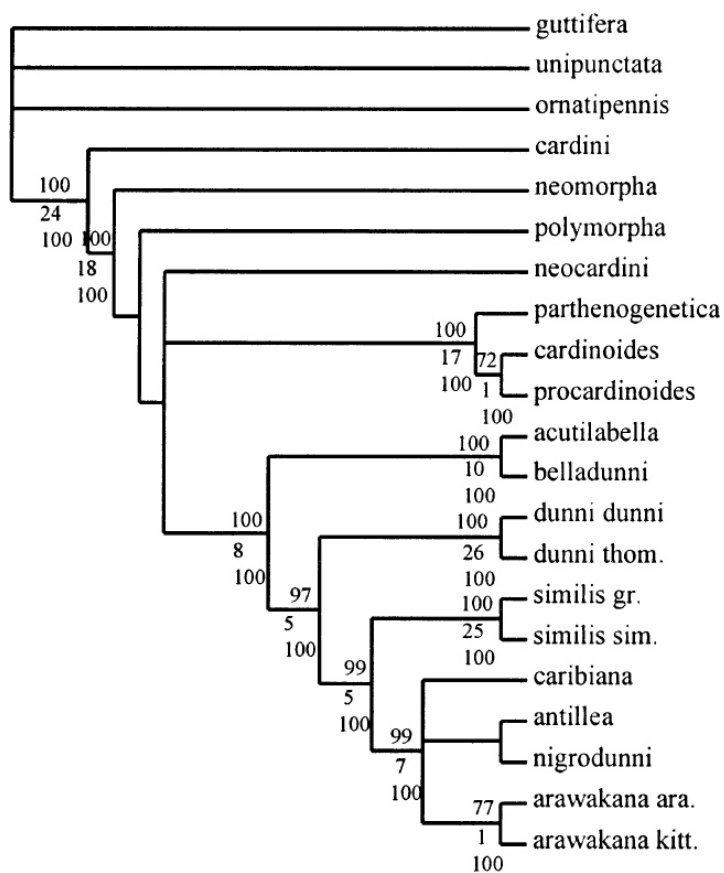

FIG. 2. Strict parsimony consensus trees of nuclear datasets. The numbers associated with each node are the maximum likelihood bootstrap, the maximum parsimony bootstrap, the decay index, and the Bayesian posterior probability (top to bottom). Only bootstrap values greater than 70 and posterior probabilities greater than 90 are noted. (A) $\mathrm{mlc}$, (B) pgd, (C) sod, (D) all nuclear DNA combined (note that there are no ML bootstrap values on this tree). 
TABLE 7. $P$-values of pairwise comparisons for the partition homogeneity tests. Bonferroni correction of $P=0.05$ is $P=0.003$; thus, no tests are significant.

\begin{tabular}{lcccccc}
\hline \hline & pgd & mlc & sod & cytB & COII & $16 S$ \\
\hline pgd & - & & & & & \\
mlc & 0.01 & - & & & & \\
sod & 0.02 & 0.01 & - & & & \\
cytB & 0.23 & 0.07 & 0.06 & - & & \\
COII & 0.04 & 0.04 & 0.37 & 0.96 & $-\overline{1}$ & - \\
l6S & 0.01 & 0.01 & 0.02 & 0.89 & 0.71 & - \\
\hline
\end{tabular}

supported by the molecular data and that $D$. neocardini was more closely aligned with the $D$. parthenogenetica, D. cardinoides, and $D$. procardinoides clade than it was with either the D. acutilabella/D. dunni subgroup clade (33 additional steps, $P<0.0001)$ or with the D. neomorpha/D. polymorpha clade (41 additional steps, $P<0.0001)$ as was suggested by the inversion and male genitalia data, respectively (Heed 1962; Heed and Russell 1971).

What is the likely source of colonists for the D. dunni subgroup radiation? - We investigated the likely geographical source of colonists for the derived island species by testing whether the next closest species clade having a predominately South American distribution, namely the $D$. neocardini, D. parthenogenetica, $D$. cardinoides, and $D$. procardinoides clade, could substitute for $D$. acutilabella and $D$. belladunni as sister taxa to the island species on Puerto Rico and the Lesser Antilles, and we were able to reject this hypothesis (12 additional steps, $P$ $<0.0027)$.

What is the colonization history of the Caribbean species? - We rejected a north to south (37 additional steps, $P<0.001$ ) as well as a south to north (81 additional steps, $P<0.001)$ stepping-stone pattern of colonization occurring in this group's history. We also rejected the hypothesis that there was an invasion of the islands by a light species from the north and a separate invasion by a dark species from the south (44 additional steps; $P<0.001)$ meeting midstream.

Is our molecular phylogeny concordant with previously generated inversion chromosome and isozyme phylogenies? - The topology defined by the inversion phylogeny (Heed and Russell 1971, W. B. Heed, pers. comm.) was significantly longer than our molecular phylogeny (112 extra steps, $P<0.001$ ). Similarly, the topology produced from the isozyme data (Napp and Cordeiro 1981) was significantly different (287 differences, $P<0.001$ ).

We also used the posterior probability results from the Bayesian analysis of the total dataset to test these same hypotheses. Because all of the alternative tree topologies identified above involve the breaking of a clade with a posterior probability of 100, all alternatives can be rejected at the $P<$ 0.001 level (each Bayesian analysis was run for 10 million generations, sampled each 1000 generation, and always less than 1000 trees were discarded for the burn-in; hence, the alternative to a clade with 100 posterior probability is roughly 1/9000). Therefore, hypothesis testing using the Bayesian results agreed with the results of the nonparametric Wilcoxon signed rank tests.

\section{Discussion}

Much theoretical work address the role of polymorphism in the production of phenotypic diversification (Futuyma 1988; Mayr 1942; Simpson 1953; West-Eberhard 2003). The goal of this study was to use abdominal pigmentation as an example phenotype for understanding how a trait evolves to produce the differences among species that are observed today. In the sections that follow, we first establish the phylogenetic history of the group, and then use this to infer an evolutionary history of pigmentation pattern variation.

\section{The Phylogeny of the Drosophila cardini Group}

The combined molecular dataset produced a well-resolved tree (Figure 3) with strong support for the monophyly of the $D$. cardini group as a whole. Most phylogenies (especially those produced from the nuclear datasets) placed $D$. cardini as the most ancestral species within the group. This relationship is concordant with the cytological data, which show that $D$. cardini is the most unique because it has six metaphase chromosome pairs whereas the remaining species in the group have four (Heed and Russell 1971).

The D. cardini subgroup mainland species represent a relatively old group, in which species diverged from one another as many as 6.6 million years ago (using the conservative estimate of $1 \%$ genetic divergence equal to one million years for mtDNA; DeSalle et al. 1987). The species of this subgroup clearly do not form a monophyletic group, but rather are paraphyletic. Paraphyly of the $D$. cardini subgroup is not surprising: the $D$. dunni subgroup species were originally separated from the rest of the group based on pigmentation, chromosomal inversion patterns, and geographic distribution (Heed and Krishnamurthy 1959); the D. cardini group was established to contain all the members not in the $D$. dunni subgroup (Heed 1962). It is now clear that the radiation of the $D$. dunni subgroup species from the mainland to the islands resulted in paraphyly of the D. cardini subgroup.

When using multiple sequences from individual species, we could not resolve three species of the D. cardini subgroup:

D. procardinoides, D. cardinoides, and D. parthenogenetica. They therefore appear to be of relatively recent origin, are still segregating for variation at both nuclear and mitochondrial loci, and may be hybridizing in areas where they are sympatric. Indeed, Heed (1962) previously grouped these species due to their similarity in male genitalia and because each successfully interbreeds with the other two in at least one direction. Drosophila procardinoides is restricted to the high elevation Andes of Bolivia and Peru (Heed 1963), and is therefore unlikely to encounter the other two species. Although $D$. cardinoides and D. parthenogenetica were previously thought to overlap only in Central America, they have recently been found to have a more extensive distribution (De Toni et al. 2005), and therefore sympatric distributions with potential for hybridization.

The placement of $D$. neocardini as the sister taxon to the $D$. procardinoides, D. cardinoides, and D. parthenogenetica clade contrasts with the inversion and male genitalia data, which either align $D$. neocardini with $D$. acutilabella and the other island species (based on inversion data; Heed and Russell 


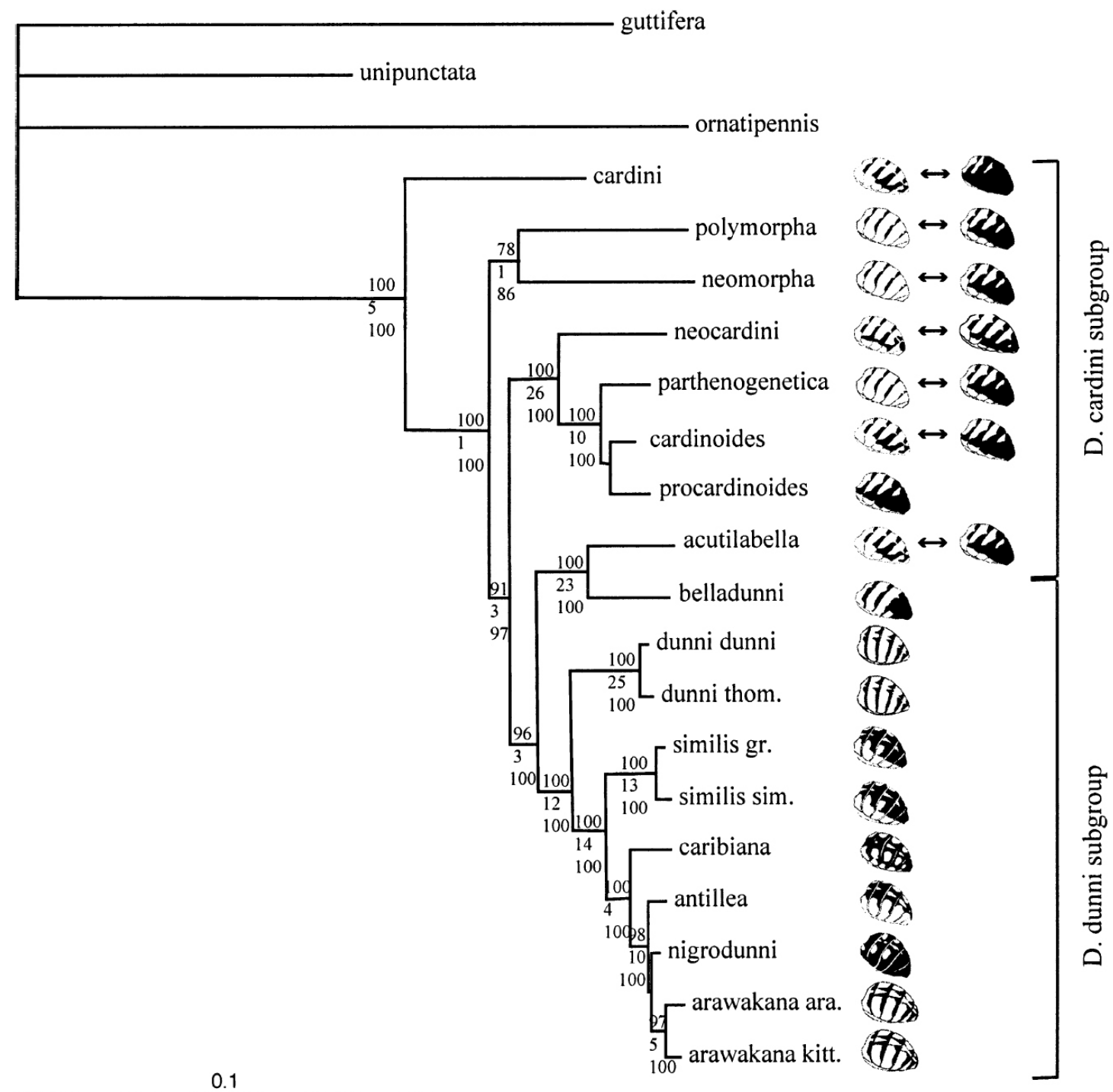

Fig. 3. Bayesian consensus tree of the Drosophila cardini group species relationships. The number above the node is the maximum parsimony (MP) bootstrap value, below the node is the MP decay index, and the bottom number is the Bayesian posterior probability. Extremes of adult abdominal pigmentation are shown for each polymorphic species. Brackets demarcate the two different subgroups, with the $D$. dunni subgroup species separated from the remaining members of the group based on their geographic distribution, cline in pigmentation, and cytology (Heed and Krishnamurthy 1959).

1971) or with D. neomorpha and D. polymorpha (based on the male genitalia data; Heed 1962). The conflict in these different datasets with respect to the placement of D. neocardini within the $D$. cardini group most likely derives from this species retaining an assortment of ancestral traits which differentially link it with the island species in the case of inversion patterns and with D. polymorpha and D. neomorpha in the case of male genitalia. However, the sequence data are clear on the placement of D. neocardini: constraining $D$. neocardini to be aligned with D. acutilabella and the D. dunni subgroup species or with $D$. neomorpha and D. polymorpha produces trees which are significantly longer than the tree with $D$. neocardini in a clade with $D$. cardinoides, $D$. parthenogenetica, and D. procardinoides.

Also strongly supported is a monophyletic clade containing the majority of the island D. dunni subgroup species. These species separated from the mainland species and radiated across the Caribbean islands. The only D. dunni subgroup species not included in this monophyletic clade is $D$. belladunni, which Heed originally considered part of the D. cardini subgroup because it does not cross well with the other island species (although females will cross with males of other island species; Heed and Krishnamurthy 1959). Upon discovering that it does not cross well with the continental species either, and has only three inversion differences from $D$. acutilabella, Heed later assigned D. belladunni to the D. dunni subgroup (Heed and Russell 1971). The assignment of these sister species, D. belladunni and D. acutilabella, to either the $D$. cardini or $D$. dunni subgroup is arbitrary systematically. However, both species lack the dorsal midline pigmented stripes that are characteristic of the D. dunni subgroup species that may represent a novel developmental aspect to the 
pigmentation system. Hence, we favor the assignment of $D$. belladunni and $D$. acutilabella to the $D$. cardini subgroup.

Within the $D$. dunni subgroup, D. antillea, D. nigrodunni, and $D$. arawakana have been termed the "nigrodunni complex" because of similarity in male genitalia morphology (Heed 1962) and their limited ability to interbreed (Heed and Krishnamurthy 1959). Wilder and Hollocher (2003) performed an in-depth analysis of this group and found that although variation at nuclear loci within this complex could not resolve species, a mitochondrial and a Y-linked locus provided more genetic differentiation due to their smaller effective sizes. This information, combined with the dramatic pigmentation divergence and reproductive isolation that exists among these species, indicates that members of the nigrodunni complex of the $D$. dunni subgroup are distinct species, albeit very recently derived. The polytene chromosome inversion data generally agree with these island species relationships, although they are much less resolved than the sequence data (identifying only two groupings among the island species; Heed and Russell 1971).

The isozyme data (Napp and Cordeiro 1981) show the most discordance with the other datasets. These data do agree with the grouping of D. caribiana, D. nigrodunni, and $D$. arawakana $(D$. similis and $D$. antillea were not included in the protein analysis) and place these species closer to D. acutilabella and D. belladunni than to most other species in the D. cardini group. However, in the protein analysis, D. dunni does not fall into the island group and is aligned instead with one of the most distance species (D. neomorpha). In addition, the isozyme data align $D$. cardini with $D$. cardinoides which is separated from the taxa determined to be its sister taxa by all other analyses, D. parthenogenetica and D. procardinoides. These two species are instead aligned with $D$. polymorpha. A certain amount of gene flow can often be hypothesized to explain inconsistencies between mitochondrial and nuclear isozyme data (because these two genetic systems can be affected very differently by hybridization patterns); however, in this case, the inversion data which are also nuclear and should reflect similar patterns of gene flow agree more with the mitochondrial data than the isozyme data, as do the nuclear sequence data. Therefore, the inconsistency is more likely due to problems of homoplasy inherent in isozyme data rather than the different types of molecular information reflecting different evolutionary histories for the species in the $D$. cardini group.

Biogeography of the D. dunni Subgroup and Changes in Abdominal Pigmentation

The monophyly of the D. dunni species on Puerto Rico and the Lesser Antilles indicates that they are all derived from a single common ancestor and have not resulted from separate colonization events from mainland sources. Further, the species in the sister clade to this group, D. belladunni and $D$. acutilabella, are distributed in North America and the Greater Antilles (Table1). Hence, the most likely source of the Puerto Rico and Lesser Antilles D. dunni species is from North/Central America or the Greater Antilles rather than directly from South America.

The interspecific cline the D. dunni species form across the islands is an unusual situation, and two primary factors are

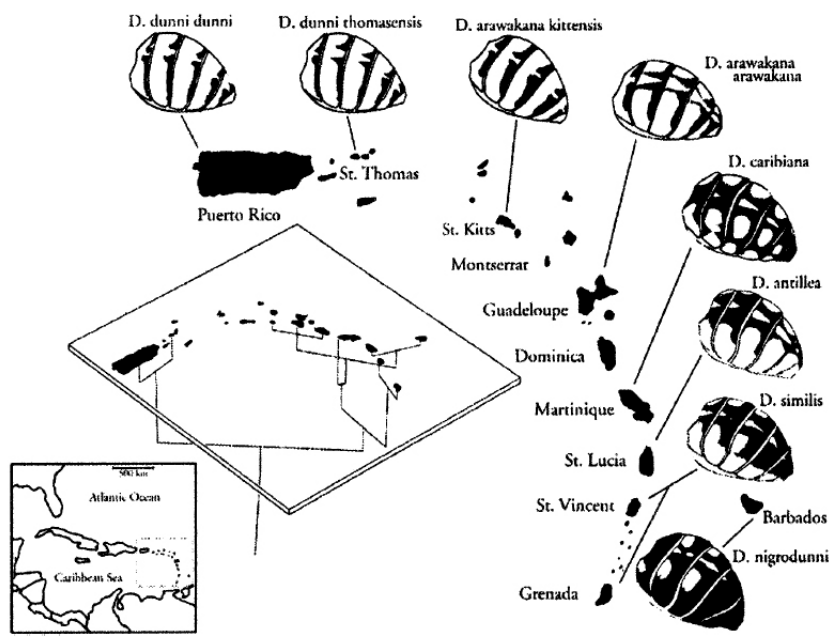

FIG. 4. The abdominal pigmentation phenotypes of members of the Drosophila dunni subgroup Caribbean island morphological cline (modified from Heed and Krishnamurthy 1959). Phylogenetic relationships are superimposed on the geography of the islands on which each species or subspecies occurs.

potentially responsible for such a cline: colonization history or natural selection. We tested whether colonization across the islands followed an ordered, stepping-stone model from the north (beginning with Puerto Rico) to the south (ending in Grenada/St. Vincent) to account for the regular pattern of pigmentation across the islands. Results of this test indicate that the north to south hypothesis could be ruled out by the sequence data, as could an alternative hypothesis of colonization occurring in a stepping-stone fashion in the opposite direction (from south to north). We also investigated whether the cline emerged as a result of a dark species invading from the south and a light species from the north meeting in the middle of the island chain. We rejected this colonization hypothesis as well. Therefore, colonization history is not at all associated with the resulting distribution of pigmentation across the islands (Figure 4). Rather, the species relationships within the D. dunni subgroup indicate that colonization occurred in a rather haphazard manner, beginning with Puerto Rico, then proceeding to Grenada/St. Vincent, followed by colonization of Martinique and finally the remaining islands of the Lesser Antilles. Particularly interesting is the brief amount of evolutionary time separating divergent phenotypes. Wilder and Hollocher (2003) estimated that two of the most diverse phenotypic forms (D. arawakana and $D$. nigrodunni) diverged less than 100,000 years ago. Hence, all available evidence points to natural selection as having been involved in shaping this interspecific cline in abdominal pigmentation across the Caribbean islands.

Monomorphic Descendants Emerged from Polymorphic Ancestors

The existence of both variable and monomorphic species in the D. cardini group makes it useful for examining the direction of phenotypic evolution. Of the members of the in- 
traspecifically variable $D$. cardini subgroup, only $D$. procardinoides does not display variation for this trait (Heed 1963). Drosophila cardini, D. cardinoides, D. polymorpha, D. parthenogenetica, D. acutilabella, D. neomorpha, and D. neocardini all present morphs that range from light to dark (Heed 1962, 1963; Stalker 1953). In contrast, members of the D. dunni subgroup display little to no intraspecific variation in abdominal pigmentation (Heed 1963; Hollocher et al. 2000a). The abdominal pigmentation morphs are presented in conjunction with the phylogenetic hypothesis for the group in Figure 3.

We investigated the phylogenetic position of polymorphic and monomorphic species of the $D$. cardini group with the hypothesis that polymorphic ancestors have given rise to monomorphic descendants. Examination of the tree topology indicates that an ancestral polymorphic state likely existed prior to speciation of the entire D. cardini group, and that monomorphism has evolved independently two or three times. One occurrence is the case of $D$. procardinoides. Two equally parsimonious scenarios could account for the remaining monomorphic species that include all of the island endemic species. First, given an ancestral polymorphic state, monomorphism could have arisen one time in the ancestor of the D. dunni subgroup plus D. acutilabella, with a later reversal to polymorphism in D. acutilabella. Alternatively, monomorphism could have evolved independently in $D$. belladunni and in the ancestor to the clade containing the remainder of the $D$. dunni subgroup species.

\section{Range Size and Morphological Variation}

The polymorphic species of the group have geographic ranges presented in Table 1. Most of the polymorphic species are distributed on the mainland, with the majority of these polymorphic species having large range sizes. In contrast, all but one of the monomorphic species have highly restricted island distributions; that is, most species are confined to a single island in the Caribbean. The only species that is monomorphic and not an island endemic is D. procardinoides. Interestingly, D. procardinoides also has a restricted distribution: the Andes of Bolivia and Peru.

Thus, the general pattern observed in the D. cardini group is monomorphic species with restricted distributions and polymorphic species with wide-ranging distributions. If pigmentation in this group is hypothesized to result from natural selection, it is possible that local adaptation maintains polymorphic species on the mainland given their widespread distributions and exposure to a range of environments, while smaller population sizes and limited habitat types result in monomorphic species.

\section{Plasticity and Phenotypic Diversification}

The diversity of abdominal pigmentation in the D. cardini group and the repeated evolution of monomorphism indicate that the developmental control of abdominal pigmentation is highly malleable. Supporting this assertion are earlier investigations on the developmental basis of abdominal pigmentation in this group, which resulted in some intraspecific polymorphisms being categorized as environmentally influenced (D. cardini, D. cardinoides, and D. acutilabella; Heed 1963), and others genetically controlled (D. polymorpha, D. neomorpha, D. neocardini, and D. parthenogenetica; da Cunha 1949; Heed 1963; Martinez and Cordeiro 1970). Because these classifications have not yet been investigated in detail, it remains unclear whether genetically controlled polymorphism has evolved from environmentally induced polymorphism, vice versa, or both in this system. However, as previously asserted, it is clear that monomorphism has evolved from a polymorphic ancestral state. The $D$. cardini group may therefore be an excellent system for future studies investigating the transition from a polymorphic ancestral state to genetic divergence in and fixation of phenotypes, how that process correlates with niche exploitation and species radiations, and if plasticity contributes to this process (West-Eberhard 2003; Schlichting 2004).

\section{Conclusion}

Abdominal pigmentation is highly variable in the genus Drosophila overall (True 2003), and much effort is currently focused on deciphering the developmental genetic mechanisms underlying divergence in this trait (Hollocher et al. 2000b; Kopp et al. 2000; Wittkopp et al. 2002; Gompel and Carroll 2003; True 2003; Brisson et al. 2004; Wilder et al. 2004). Very little, however, is known about how these trait differences evolve within the context of natural populations. Phylogenetic patterns within the $D$. cardini group suggest that control of pigmentation development is highly malleable. In widespread species, phenotypes are both environmentally and genetically polymorphic. Polymorphism, in turn, can be easily fixed into monomorphic genetic responses in geographically isolated species. Additionally, the monomorphic island species form a cline of pigmentation across the Caribbean that is discordant with phylogeny, suggesting that natural selection has played an important role in shaping the pigmentation phenotype in this group.

\section{Acknowledgments}

We are grateful for the help of D. Bruck, K. M. Rodriguez-Clark, E. G. Dyreson, E. G. Schielke, and B. A. Heller in securing Drosophila samples; K. Crandall for advice on analyses; and P. Simon, D. Kutzler, S. Gray, and K. E. Dickerson for technical assistance. Thanks also to N. Weeks (Director of Forestry in the Ministry of Agriculture, St. Vincent), M. Leone (Smithsonian Tropical Research Institute, Panama), J. and E. de Jesús Marcano (Universidad Autónoma de Santo Domingo, Dominican Republic), C. Pierre, and Mr. Zamore (Ministry of Agriculture, Dominica) for their help securing permission to collect and export Drosophila; and D. Knott and D. Wayson (USDA) for permission to import flies to the USA (USDA/APHIS/ PPQ permit 952787). Warm thanks to M. George-Dill, manager of the Springfield Plantation and member of the Board of Directors of the Springfield Center for Environmental Protection Training Education and Research in Dominica for all of her professional help and hospitality. We would especially like to thank W. Heed and E. Dyreson for several illuminating discussions and help with species identifications. Thanks to A. Shingleton, T. Frankino, R. Bickel, J. Das, A. McGregor, and two anonymous reviewers for helpful comments on this manuscript. This work was supported by funds awarded to $\mathrm{HH}$ from the National Science Foundation, Alfred P. Sloan Foundation, Henry Luce Foundation, Princeton University, and the University of Notre Dame, and by funds awarded to JAB by National Science Foundation dissertation improvement grant number DEB0104977. JAB is a Howard Hughes Medical Institute Predoctoral Fellow. 
Literature Cited

Bremer, K. 1994. Branch support and tree stability. Cladistics 10: $295-$ 304.

Brisson, J. A., A. R. Templeton, and I. Duncan. 2004. Population genetics of the developmental gene optomotor-blind (omb) in Drosophila polymorpha: evidence for a role in abdominal pigmentation variation. Genetics 168: 1,999-2,010.

Brisson, J. A., D. C. De Toni, I. Duncan, and A. R. Templeton. 2005. Abdominal pigmentation variation in Drosophila polymorpha: geographic variation in the trait, and underlying phylogeography. Evolution 59: 1,046-1,059.

Brower, A. V. Z., and R. DeSalle. 1994. Practical and theoretical considerations for choice of a DNA sequence region in insect molecular systematics, with a short review of published studies using nuclear gene regions. Ann. Entomol. Soc. Am. 87: 702-716.

Christensen, A. C., and J. C. Lucchesi. 1984. Cloning of the Drosophila 6-phosphogluconate dehydrogenase gene pgd. Genetics 107: s20.

da Cunha, A. B. 1949. Genetic analysis of the polymorphism of color pattern in Drosophila polymorpha. Evolution 3: 239-251.

- - - 1955. Sobre duas racas de Drosophila neocardini streisinger. Rev. Brasil. Biol. 15: 117-125.

De Toni, D. C., J. A. Brisson, P. R. P. Hofmann, M. Martins, and H. Hollocher. 2005. First record of Drosophila parthenogenetica and D. neomorpha, cardini group, Heed, 1962 (Drosophila, Drosophilidae), in Brazil. Dros. Inf. Serv. 88: 33-38.

DeSalle, R. 1995. Molecular approaches to biogeographic analysis of Hawaiian Drosophilidae. Pp. 72-89 in W. L. Wagner and V. A. Funk, eds. Hawaiian Biogeography: Evolution on a Hot Spot Archipelago. Smithsonian Institute Press, Washington, DC.

DeSalle, R., T. Freedman, E. M. Prager, and A. C. Wilson. 1987. Tempo and mode of sequence evolution in mitochondrial DNA of Hawaiian Drosophila. J. Mol. Evol. 26: 157-164.

Ellers, J., and C. L. Boggs. 2003. The evolution of wing color: male mate choice opposes adaptive wing color divergence in Colias butterflies. Evolution 57: 1,100-1,106.

Farris, J. S., M. Kallersjo, A. G. Kluge, and C. Bult. 1994. Testing significance of incongruence. Cladistics 10: 315-319.

- - - 1995. Constructing a significance test for incongruence. Syst. Biol. 44: 570-572.

Felsenstein, J. 1985. Confidence limits on phylogenies: an approach using the bootstrap. Evolution 39: 783-791.

Futch, D. G. 1962. Hybridization studies within the cardini species group of the genus Drosophila. Univ. Texas Publ. 6205: 539-554.

Futuyma, D. J. 1988. The evolution of ecological specialization. Annu. Rev. Ecol. Syst. 19: 207-233.

Gompel, N., and S. B. Carroll. 2003. Genetic mechanisms and constraints governing the evolution of correlated traits in drosophilid flies. Nature 424: 931-935.

Hebert, P. D. N., and C. J. Emery. 1990. The adaptive significance of cuticular pigmentation in Daphnia. Funct. Ecol. 4: 703-710.

Heed, W. B. 1962. Genetic characteristics of island populations. Univ. Texas Publ. 6205: 173-206.

- - - 1963. Density and distribution of Drosophila polymorpha and its color alleles in South America. Evolution 17: 502-518.

Heed, W. B., and N. B. Krishnamurthy. 1959. Genetic studies on the cardini group of Drosophila in the West Indies. Univ. Texas Publ. 5914: 155-179.

Heed, W. B., and J. S. Russell. 1971. Phylogeny and population structure in island and continental species of the cardini group of Drosophila studied by inversion analysis. Univ. Texas Publ. 7103: 91130.

Hollocher, H. 1996. Island hopping in Drosophila: Patterns and processes. Philos. Trans. R. Soc. Lond. B 351: 735-743.

Hollocher, H., J. L. Hatcher, and E. G. Dyreson. 2000a. Evolution of abdominal pigmentation differences across species in the Drosophila dunni subgroup. Evolution 54: 2,046-2,056.
- - - 2000b. Genetic and developmental analysis of abdominal pigmentation differences across species in the Drosophila dunni subgroup. Evolution 54: 2,057-2,071.

Huelsenbeck, J. P., and F. Ronquist. 2001. MrBayes: Bayesian inference of phylogenetic trees. Bioinformatics 17: 754-755.

Kopp, A., I. Duncan, and S. B. Carroll. 2000. Genetic control and evolution of sexually dimorphic characters in Drosophila. Nature 408: 553-559.

Machado, M. X., D. C. De Toni, and P. R. P. Hofmann. 2001. Abdominal pigmentation polymorphism of Drosophila polymorpha (Dobzhansky and Pavan, 1943) collected on Ilha de Santa Catarina and neighboring islands. Biotemas 14: 87-107.

Maddison, W. P., and D. R. Maddison. 2000. MacClade, Analysis of Phylogeny and Character Evolution. Ver. 4.0. Sinauer, Sunderland, MA.

Majerus, M. E. N. 1998. Melanism: Evolution in Action. Oxford Univ. Press, Oxford, U.K.

Martinez, M. N., and A. R. Cordeiro. 1970. Modifiers of color pattern genes in Drosophila polymorpha. Genetics 64: 573-587.

Mayr, E. 1942. Systematics and the Origin of Species. Columbia Univ. Press, New York.

- - -. 1963. Animal Species and Evolution. Harvard Univ. Press, Cambridge, U.K

Nachman, M. W., H. E. Hoekstra, and S. L. D'Agostino. 2003. The genetic basis of adaptive melanism in pocket mice. Proc. Natl. Acad. Sci. USA 100:5268-5273.

Napp, M., and A. R. Cordeiro. 1981. Interspecific relationships in the cardini group of Drosophila studied by electrophoresis. Rev. Brasil. Biol. 4: 537-547.

Posada, D., and K. A. Crandall. 1998. ModelTest: testing the model of DNA substitution. Bioinformatics 14: 817-818.

Rambaut, A., and A. Drummond. 2004. Tracer. University of Oxford, Oxford, U.K.

Rand, D. 1992. A dot blot hybridization method for estimating the frequencies of mitochondrial DNA haplotypes in experimental populations of Drosophila. Dros. Inf. Serv. 71: 176-180.

Remsen, J., and P. O'Grady. 2002. Phylogeny of Drosophilinae (Diptera: Drosophilidae), with comments on combined analysis and character support. Mol. Phylogenet. Evol. 24: 249-264.

Schlichting, C. D. 2004. The role of phenotypic plasticity in diversification. Pp. 191-200 in T. J. DeWitt and S. M. Scheiner, eds. Phenotypic Plasticity: Functional and Conceptual Approaches. Oxford Univ. Press, New York.

Simpson, G. G. 1953. The Major Features of Evolution. Simon and Schuster, New York.

Sorenson, M. D. 1999. TreeRot. Ver. 2. Boston University, Boston, MA.

Spicer, G. S. 1995. Phylogenetic utility of the mitochondrial cytochrome oxidase gene: molecular evolution of the Drosophila buzzatti species complex. J. Mol. Evol. 41: 749-759.

Stalker, H. D. 1953. Taxonomy and hybridization in the cardini group of Drosophila. Ann. Entomol. Soc. Am. 46: 343-358.

Streisinger, G. 1946. The cardini species group of the genus Drosophila. J. NY Entomol. Soc. 54: 105-113.

Sturtevant, A. H. 1942. The classification of the genus Drosophila, with descriptions of nine new species. Univ. Texas Publ. 4213: 5-51.

Swofford, D. L. 2000. PAUP*, Phylogenetic Analysis Using Parsimony (*and Other Methods). Ver. 4 for Apple Macintosh, Intel, Linuz and SGI/Irix. Sinauer, Sunderland, MA.

Templeton, A. R. 1983. Phylogenetic inference from restriction endonuclease cleavage site maps with particular reference to the evolution of humans and the apes. Evolution 37: 221-244.

Thompson, J. D., D. G. Higgins, and T. J. Gibson. 1994. Clustal W: improving the sensitivity of progressive multiple sequence alignment through sequence weighting, position-specific gap penalties and weight matrix choice. Nucleic Acids Res. 22: 4,673-4,680. 
True, J. R. 2003. Insect melanism: the molecules matter. Trends Ecol. Evol. 18: 640-647.

Vilela, C. R., A. F. G. da Silva, and F. d. M. Sene. 2002. Preliminary data on the geographical distribution of Drosophila species within morphoclimatic domains of Brazil. Rev. Brasl. Entomol. 46: 139148.

West-Eberhard, M. J. 2003. Developmental Plasticity and Evolution. Oxford Univ. Press, New York.

Wilder, J. A., and H. Hollocher. 2003. Recent radiation of endemic Caribbean Drosophila of the dunni subgroup inferred from mul- tilocus DNA sequence variation. Evolution 57: 2,566-2,579.

Wilder, J. A., E. G. Dyreson, R. J. O'Neill, M. L. Spangler, R. Gupta, A. S. Wilder, and H. Hollocher. 2004. Contrasting modes of natural selection acting on pigmentation genes in the Drosophila dunni subgroup. J. Exp. Zool. B Mol. Dev. Evol. 302B: 469-482.

Wittkopp, P. J., K. Vaccaro, and S. B. Carroll. 2002. Evolution of yellow gene regulation and pigmentation in Drosophila. Curr. Biol. 12: $1,547-1,556$

Corresponding Editor: M. Peterson 